\title{
Adapting to a remote life Using a work environment at home to our advantage at University of North Florida Special Collections
}

$\mathbf{Y}$ ou might think that there would not be enough to do at home for a staff working with archival materials - after all, most of the collection consists of rare items that never leave the building. When it began to look like the University of North Florida (UNF) would be closed in March 2020, our small team in the Thomas G. Carpenter Library Special Collections Department had to get creative.

\section{A little background}

We are a department of three-and-a-half: the head of special collections, the special collections coordinator, a visiting university archives librarian, and a part-time employee working on a grant project. Special Collections and University Archives at UNF is a merged collection of university history and local history collections. ${ }^{1}$ Our university is fairly new, started in 1972, and the original archivist established the collection and curated it until her retirement in 2012.

After 2012, there were several years with either no archivist in charge of the collection or lack of administrative support of the archives. Little processing work was accomplished, and few finding aids were created. Despite the lack of activity, several large collections were donated to special collections, and numerous university archival items were left at the door.

In 2018, a new head of special collections and university archives was hired, and with the support of the new library dean, the department slowly started moving forward again. We began processing some of the new collections, and our legacy finding aids were migrated to ArchivesSpace, a database used to manage archival content. As the semesters progressed, we found ourselves spending more time with students and falling behind in our arrangement and description tasks. From 2018 until early 2020 , there were only two full-time staff providing access to the collection and processing the backlog. With UNF's 50th anniversary looming on the horizon, we received permission to hire a visiting university archives librarian to start sorting through some of the backlog, creating a timeline of university history, and preparing us for questions that would surely be coming about the founding of our institution.

\section{Our remote work experiences}

Although we had been hearing about the COVID-19 outbreak for weeks, UNF made its decision fairly quickly in mid-March to remain closed after Spring Break. Faculty in the library started meeting the week before Spring Break to strategize our remote work plans. In special collections, we scrambled to think of projects to work on while we coordinated with IT to create remote desktop access and to borrow library laptops.

The head of special collections met with each staff member to discuss the status of current projects and ways they could be continued remotely. Although we did not want to take

Susan Swiatosz is head of special collections and university archives at the University of North Florida, email: s.swiatosz@unf.edu

() 2021 Susan Swiatosz 


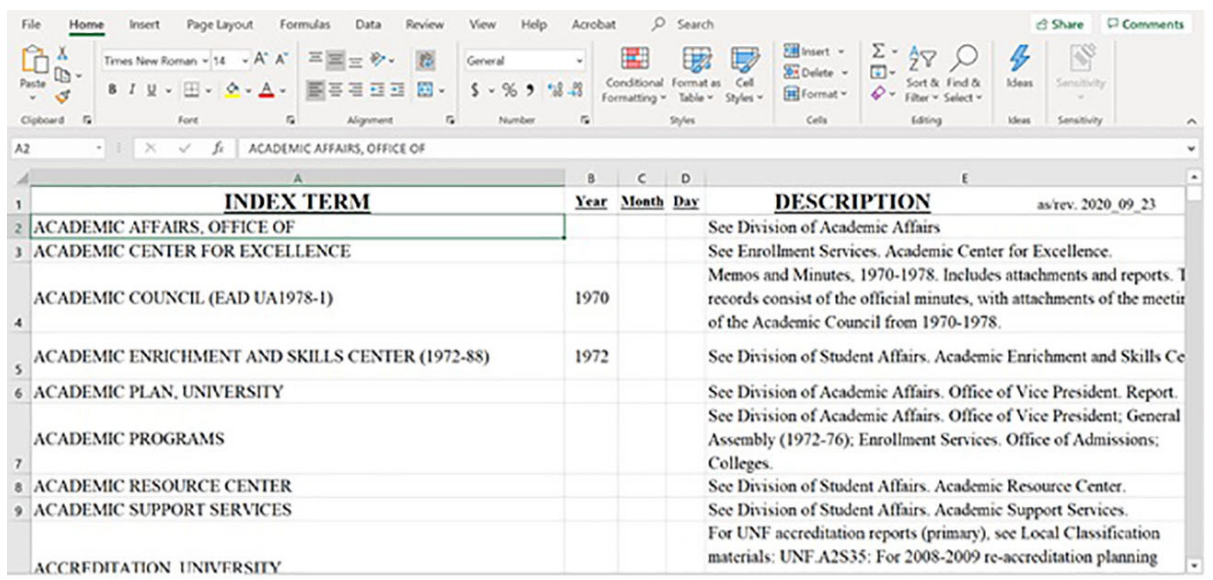

Figure 1: Portion of the UNF index of the university archives Excel spreadsheet.

archival collection items out of special collections, we determined that it was okay for administrative files and finding aids to leave the building. We innocently thought we would be back in a couple of weeks, so we weren't too worried about leaving our collections behind.

As it would happen, a week after the new visiting librarian started, we closed the library doors and started working from home. We had hired someone with experience in cleaning up backlogs in university archives, and he was able to hit the ground running. Within the first couple of days in the collection, the visiting librarian discovered an index to the university archives. It was on paper only and was not complete, but it was a starting point. Over the next several weeks, the visiting librarian became familiar with the extent of the collection through the index. He entered the information into an Excel spreadsheet so that it would be searchable and added information that did not exist in the original paper document, such as dates and more complete descriptions (see Figure 1).

The index project ended up being a great training tool and gave the visiting librarian a broad overview of the collection. In ensuing weeks, he would go on to draft a university history timeline, start a file of items that could be potential social media postings throughout the anniversary year, and worked with one of the founding faculty members to create a list of original staff and faculty.
In the meantime, the special collections coordinator had recently taken ArchivesSpace training and was itching to enter a new finding aid into the database. We chose to begin with a fairly large new collection that we had recently finished processing. Since the coordinator did the majority of the processing, she was the most familiar with the material.

After a few bumps in the road, we started figuring out some standards. We found that 10-to-15 subject categories are sufficient for descriptive purposes, and we created boilerplate terminology for "Conditions Governing Use" $^{2}$ and "Preferred Citation" 3 so that there was consistency in all our finding aids. Over the summer, the coordinator created four new finding aids and started cleaning up six more legacy finding aids, combining the collection information with their respective container lists, which were separate documents. ${ }^{4}$ Since then, she has started creating a training manual for interns and student workers (see Figure 2) and has coordinated with our Digital Projects team to link the new finding aids with scanned material from the collections.

Our part-time employee was hired to work with a large collection that came with grant funding. A recent UNF graduate with a degree in History, she is the third person in a year to work on the project. Although she was somewhat familiar with the collection when she started in her position, she experienced "trial by fire" when the donor suddenly re- 
1. There are two ways to create a resource record. The first option for creating a Resource Record is to Select the Spawn from the drop-down menu of your completed Accession Record, then select Resource.

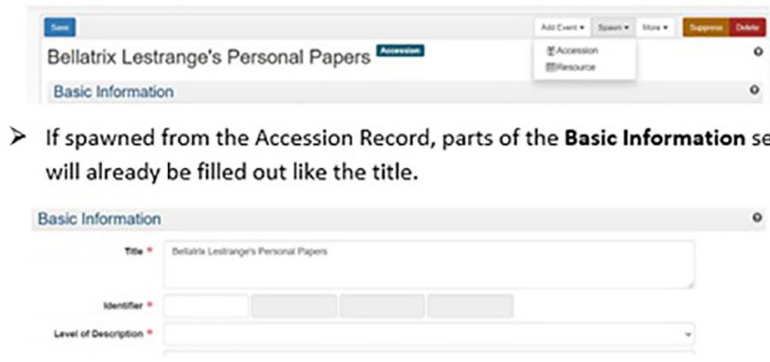

Figure 2: Portion of the ArchivesSpace Training Manual for interns and student workers.

quested to review the collection in fall 2019. We had discovered several documents containing personal information, and the donor had 78 banker's boxes and 14 archival document cases returned to their facility to reevaluate what had been donated. She created spreadsheets to document the items sent back to the donor and the 30 boxes that were ultimately approved and returned to UNF Special Collections in January 2020.

At the time we closed for the pandemic, she had inventoried the returned collection and checked it against her spreadsheets. She was able to spend the next few months updating our container list inventory to reflect the changes in the collection. She also compared the finding aid with the spreadsheet our Digital Projects team used to track digitizing the collection. She cleaned up metadata, added/removed items, and added consistency to the entries.

The head of special collections and university archives had several projects she had wanted to work on and the confusion of transitioning to working remotely initially freed time that would normally be spent in meetings. It was several months before Zoom meetings became regularized. She brought home boxes of files created by the original archivist and was able to sort and organize the information. Quite a bit of information about collection acquisition was uncovered, along with procedural documents, annual statistics, and interesting tidbits about relationships with other departments on campus. Besides providing a wealth of history about the special collections department, the file cleanup project led to additional projects: creating an accession $\log$ and acquisition files, which have been useful tools for updating legacy finding aids.

\section{What we learned from the experience}

Although UNF was closed from mid-March until mid-August 2020, most of us in the library were considered essential workers and were allowed to work on site throughout the closure. The head of special collections and university archives began working in the library several days a week starting in May and by July was working full-time on site. In June and July, the special collections coordinator and the visiting university archives librarian began gradually working more in the library, as well. By the time classes started on August 17, we were all working full-time on campus, with the exception of the part-time employee who has continued to work remotely.

Being at home forced us all to up our game when it came to technology: in addition to the usual emails and texts, we kept in touch through regular Zoom meetings and learned 
all the nuances of functioning in a virtual meeting environment. We also learned the hard way the limitations of working through a VPN to access our remote desktops. The experience made us all more flexible and confident with new technology.

We also learned how to pace ourselves. In a normal office environment, you step away from your computer for meetings, workshops, and seminars. At home, the fully virtual experience was initially exhausting until we learned to take a break from our projects and take a webinar about something unrelated to archives. We also spent time reading books by local historians and articles about archival best practices, so we didn't spend all of our time in front of a computer screen.

As we have reacclimated to working in the library, we have found that the projects we completed while we were working remotely made our workflow more efficient and productive. Although we will be happy to see the eventual end of the COVID-19 pandemic and the pain and disruption caused by it, we were able to create a stronger department from our experience.

\section{Notes}

1. See https://www.unf.edu/library /specialcollections/.

2. Our standard Conditions Governing Use: "Materials in the collection may be subject to copyright and are to be used for private study, scholarship, or research in accordance with the copyright law of the United States (Title 17, United States Code). Use of reproductions of copyrighted works in excess of " fair use," may result in the user's liability for copyright infringement and be subject to the civil and criminal penalties of federal law. Visit the United States Copyright Office's website at http:// www.copyright.gov/ for further information."

3. Our standard Preferred Citation: "XYZ Collection, Thomas G. Carpenter Library, University of North Florida, Jacksonville, Florida."

4. See https://archives.unf.edu/repositories/ resources for our most recent finding aids. The new and "cleaned-up" finding aids have identifiers consistent with current best practices: 2XXX(year collection acquired).00X(number of collection acquired that year). For example, the identifier 2020.001 refers to the first accession in 2020. $\pi$

("Touching history," continued from page 65)

to contribute their unique strengths. Doing so gives students the chance to acquire knowledge beyond their own fields of expertise and, as a result, provides students with invaluable learning experiences. Henceforth, our project team aims to further our work which emphasizes the process of knowledge transfer. We will continue to transform archives into exhibits, and words into braille and audio descriptions for people with visual impairments. When circumstances regarding the current pandemic crisis allow, we hope to host another exhibition at the Hong Kong Maritime Museum, expanding upon earlier work to include more auditory and tactile displays, as well as the publication of an exhibition display guide written in text and braille.

Additionally, 12 students from the Department of Linguistics and Translation will work together to produce an audiobook on Hong Kong's lighthouse history. Finally, we will continue our partnership with the Special Education Needs Office, and hope to attract more blind and visually impaired students to take part in the LHRC Project for many years to come.

Although some students may have different needs with regards to accessing, understanding, and using information, all students have the same rights to relevant and useful information in their chosen format. As with all students, the blind and visually impaired have their own strengths and insights that can help create a balanced learning experience that benefits everyone. During the working process, the LHRC team became more familiarized with the unique needs and strengths of their visually impaired classmates. They also gained a new appreciation for "fairness" when planning and initiating the exhibition, a value which is

(continues on page 79) 